\title{
EQUAL AND EMPOWERED BY THE CREATOR
}

\author{
Pankhuri Dhiman \\ Student \\ Symbiosis Centre for Management Studies, \\ Noida, Uttar Pradesh, India
}

\author{
Pritanjali Tyagi \\ Student \\ Symbiosis Centre for Management Studies, \\ Noida, Uttar Pradesh, India
}

\begin{abstract}
Glass ceilinfg effect as defined by the oxford dictionary Glass ceiling to be an unacknowledged barrier that prevents minorities or women from advancing in their profession. And this research article very explains how we all were created equal and powered by the god, the creator and it is us who have created several barriers for our fellow humans living in the world created by the god.
\end{abstract}

Keywords- Glass ceiling effect, equality, pull her down syndrome

\section{INTRODUCTION}

"I was a woman; for suddenly my wings collapsed, ether closed in around my head like an impenetrable crystal vault, and I fell...."this is a phrase from a never performed play Gabriel, by a French feminist author George Sand introducing the concept of the glass ceiling to the world. What we understand the glass ceiling to be, is an invisible glass box trapping a woman inside, where she can see her goal but cannot reach it. In this article, we will touch upon the topic of what is the glass ceiling effect? In this world where men are traveling up the glass escalator are women still trapped under the glass ceiling? And is it right to use the phrase "break the glass ceiling?

\section{WHAT IS GLASS CEILING}

The Oxford dictionary describes the Glass ceiling to be an unacknowledged barrier that prevents minorities or women from advancing in their profession. This term was coined 40 years ago by Marilyn Loden, an American management consultant and diversity advocate, in her international women's day speech.

The term Glass ceiling is often misleading as to be more precise it highlights that the women can't make it to the higher level in the hierarchy but in reality, it is not just the ceiling that is present only at the top rather it is a labyrinth which is there from the start of the career of a woman.

This is one of the major reasons why women can't make it to the higher positions as this whole process starts very early and at every step of the management women drop out, decreasing them in number. This way how can we expect them to make it to the higher position?

Instead of using the metaphor "breaking the glass ceiling", we would like to put our paramount importance upon the fact that it's not just a ceiling rather it is a sticky floor or a maze trapping her and preventing her from progressing ahead. How do you expect them to break the ceiling when they can't even reach it?

\section{PROBLEM}

We all are aware of the fact that sometimes a woman who is more qualified than her male counterparts either is not promoted or is forced to drop because of the notion that she cannot manage her household responsibilities with work. Indeed, they often have several other responsibilities to bear like marriage and childbearing, while performing their roles as wife and mothers their pace often gets slowed and this eventually makes them less challenging, but does that mean they are not capable enough? You will be surprised to know that just $10 \%$ of leadership in the workplace is represented by women.

The two main problems are the cycle of unfulfilled career expectations and the PULL HER DOWN syndrome among women which eventually spreads insecurity and can even lead to depression.

Sheryl Sandberg, in her book Lean In, fittingly talks about how many people, but especially women, feel fraudulent when they are praised for their accomplishments. Instead of feeling worthy of recognition, they feel guilty and undeserving, as if a mistake has been made. Isn't this the outcome of sexism and chauvinism being intensely lodged into the system?

Indra Nooyi also said the glass ceiling will go away when women help other women breakthrough. Women are considered ruthless and bully towards other women in the corporate world, they can not stand a strong independent lady with the ability to climb the corporate ladder as they see a potential threat in them. they thus prefer to pull them down to kill the competition. but how are women supposed to cease equality when they pull each other down to dust. Jealousy does not help with empowerment.

A prominent example to prove our point would be in the office of the president of the United States. Even though there exists no such law against a woman president there has never been one. To the best of our knowledge, there could've been a lack of female employees in the US government but climbing up the ladder we could see Kamala Harris becoming the first woman vice president and the highest-ranking female official in US history. 
Another example is of DebJani Ghosh, the first woman president of NASSCOM in more than thirty years! This shows the discrepancy between men and women in the area of technology, being so high that it is not worth noting the accomplishment of women who did manage to achieve great heights.

A solution to this could be they should be taught and made aware of this labyrinth in their maiden stage. Instead of making them fearful about this notion they must be taught to challenge themselves at every stage of their life.

I think we must focus on bridging the gap between what we talk about and walk. As a structured diversity, what we often talk about is not translated into reality. The fact behind this is that men are still constituting the majority of roles in workplaces and sometimes it is a delicate dance between valuing their male employees while promoting women's leadership. And to tackle this situation organizations must spread awareness regarding adding more diversity in workplaces. This can only be done once we have an authentic conversation with all the employees, especially males.

\section{CONCLUSION}

A Birds-eye view could be that there should be some focus upon identifying more commonalities than differences in leadership skills so that women receive equal opportunities and here what comes into play are the experiences of both genders in handling a specific situation as our ultimate goal is to make an organization sustainable in terms of diversity and women inclusion so that there exists no such ceiling called glass ceiling.

\section{REFERNCES}

[1] https://en.wikipedia.org/wiki/Glass_ceiling

https://www.fortuneindia.com/macro/how-long-

before-women-break-the-glass-ceiling-in-it/102726

https://blog.infeedo.com/7-leaders-breaking-the-

glass-ceiling-in-2020

https://www.oxfordreference.com/view/10.1093/oi/au

thority.20110803095854441

http://search.proquest.com/openview/720eed4717a40

12eb80aeb984880623c/1?pq-

origsite $=$ gscholar \&cbl $=27059$

https://youtu.be/GICS2uUGvTE

https://youtu.be/tLKQezaz2IA

https://youtu.be/DQiV18dl5qg

https://youtu.be/Yk1K1dHgXi4

https://youtu.be/9ALz_C-PRI 